\title{
Humoral immune response of pregnant goats to two Corynebacterium pseudotuberculosis bacterin formulations
}

\author{
Jordana Auad ${ }^{a^{*}}$, Julieta Ceruttia, Laura G. Cooper ${ }^{\mathrm{a}}$, Cecilia M. Camussone ${ }^{\mathrm{b}}$, \\ Natalia A. Lozano ${ }^{c}$, Francisco M. Crespo ${ }^{d}$, Alejandro Lozano ${ }^{\text {a-c }}$
}

\begin{abstract}
Caseous lymphadenitis is a chronic suppurative bacterial disease caused by Corynebacterium pseudotuberculosis, and it has a high prevalence among small ruminants. Different vaccine preparations have been employed to control this disease. The adjuvant used in the formulation is a critical factor for the improvement of vaccine efficacy. No commercial vaccines are available in Argentina. The aims of the present work were to compare the specific antibody response against a C. pseudotuberculosis whole cell vaccine formulated with a classical and an immunoestimulant adjuvant in pregnant goats, and to assess the transfer of vaccine-specific antibodies from the goat to the offspring through colostrum. Twenty three pregnant goats were vaccinated. The animals were randomly allocated to three groups: control, aluminum hydroxide $\mathrm{Al}(\mathrm{OH})_{3}$ adjuvant and a new cage-like particle adjuvant (ISPA). Antibodies (IgG) against this antigen were measured by ELISA. A robust humoral immune response was detected in vaccinated animals, with production of specific IgG. No significant differences were found between the vaccines formulated with different adjuvants. High levels of specific antibodies were detected in colostrum samples from both immunised groups, which were passively transferred from goats to offprings. No adverse local reactions in the vaccines injection sites were detected.

Key words: ISPA adjuvant, immunoglobulin G, colostrum.
\end{abstract}

\section{INTRODUCTION}

Caseous lymphadenitis, also called pseudotuberculosis, is a chronic suppurative bacterial disease caused by Corynebacterium pseudotuberculosis that presents a worldwide distribution and has a high prevalence among small ruminants, also affecting cows, horses and other domestic animals (Belchior et al 2006). In addition, it has been currently recognised as an emerging zoonotic disease (Palmero et al 2013).

There is scarce information about the prevalence of this disease in goat herds in Argentina, which appears to vary according to the geographical area and type of production system. In the North West of the country, particularly in the arid ravine of Jujuy and Salta, a 60\% prevalence of pseudotuberculosis was reported recently (Suárez et al 2016), whereas in the Chaco Salteño area the prevalence was only $15.6 \%$ (Suárez et al 2015).

Pseudotuberculosis is characterised by the formation of encapsulated abscesses containing thick, caseous pus, most frequently within peripheral lymph nodes, but also within internal lymph nodes and organs (Fontaine et al 2006). Economic losses are mainly due to the progressive

\footnotetext{
Accepted: 24.01.2018.

aLaboratorio de Inmunología Hospital Veterinario, Unidad Asociada a CONICET-Área de Cs. Agr. Ing. Bio. y S., Universidad Católica de Córdoba, Córdoba, Argentina.

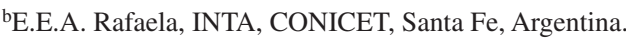

${ }^{\mathrm{c} C a ́ t e d r a ~ d e ~ I n m u n o l o g i ́ a, ~ F a c u l t a d ~ d e ~ M e d i c i n a, ~ U n i v e r s i d a d ~ C a t o ́ l i c a ~}$ de Córdoba, Córdoba, Argentina.

${ }^{\mathrm{d} E s t a b l e c i m i e n t o ~ L o s ~ T a l a s, ~ P o t r e r o ~ d e ~ G a r a y, ~ C o ́ r d o b a, ~ A r g e n t i n a . ~}$ *Corresponding author: J Auad; Av. Armada Argentina 3555 CP X5016DHK, Córdoba, Argentina; jorauad@gmail.com
}

deterioration of the general condition of the animal, which results in decreased production of wool, meat, milk, as well as reproductive disorders and confiscation of viscera at the slaughterhouse (Belchior et al 2006).

C. pseudotuberculosis can become endemic in a herd and disease eradication is problematic due to poor response to antibiotic therapy, organism ability to persist in the environment and difficulties in detecting subclinically infected animals (Al-gaabary et al 2009). The situation is aggravated by the absence of commercial vaccines available in Argentina (Palmero et al 2013).

There are numerous reports on vaccination against $C$. pseudotuberculosis in ovine species, with few studies in goats (Baird et al 2007). Different antigen preparations have been employed, such as formalin-killed bacterins, bacterial cell wall preparations, phospholipase $\mathrm{D}$ toxoid and the use of immunostimulants including oligodeoxynucleotide containing unmethylated $\mathrm{CpG}$ dinucleotides with little success (Brogden et al 1996, Brogden et al 1984, Eggleton et al 1991, Cameron et al 1972, Moura-Costa et al 2008, Brown et al 1986) .

The adjuvant used in the formulation is considered a critical factor for the improvement of vaccine efficacy. The most frequently employed adjuvants in veterinary vaccines have been Freund's incomplete adjuvant (Moura-Costa et al 2008) and $\mathrm{Al}(\mathrm{OH})_{3}$ (Fontaine et al 2006). New immunostimulant complexes (ISCOM) have been developed (Morein et al 1984, Sjölander et al 1998). These compounds induce strong cellular or humoral antigen-specific immune responses to a wide range of antigens (Sun et al 2009), being both antigens and adjuvant formulated in one and the same nanoparticle (Morein et al 2004). These nanoparticles are composed of saponins, cholesterol and phospholipids that are kept together through hydrophobic 
interactions (Morein et al 2004). The capabilities of this type of adjuvant are not restricted to particulate antigens, a recent study reported the use of ISCOMATRIX ${ }^{\mathrm{TM}}$ as an adjuvant for a Staphylococcus aureus whole cell vaccine that was evaluated in cattle with promising results (Camussone et al 2013). In addition, a new cage-like particle adjuvant (ISPA), structurally similar to ISCOM, was recently developed and evaluated in a murine model using a Trypanosoma cruzi recombinant protein antigen (Bertona et al 2017). However, the potential synergic effect of this adjuvant in the use of whole cell vaccines has not been evaluated.

In goats, the newborn lacks specific protection against the pathogenic challenges of the environment, since the syndesmocorial type of placenta does not allow the passage of antibodies. Therefore, the immunoglobulins synthesized and derived from the goat should be transferred through colostrum (Cooper et al 2014, Fernández et al 2006, Iepema et al 2008, Rudovsky et al 2008). Pregnant females should be vaccinated at approximately 4 weeks before the probable date of birth for an adequate transfer of passive immunity through colostrum to control specific infectious diseases.

The aim of the present work was to evaluate the specific antibody response against a $C$. pseudotuberculosis whole-cell vaccine formulated with $\mathrm{Al}(\mathrm{OH})_{3}$ and ISPA adjuvant in pregnant goats, and to assess the transfer of vaccine-specific antibodies from goat to offspring through colostrum.

\section{MATERIAL AND METHODS}

PREPARATION FORMALIN-KILLED C. pseudotuberculosis VACCINE (FKC)

The vaccine was formulated using the method described by Fontaine et al (2006) with slight modifications. $C$. pseudotuberculosis (UTK 224), previously characterised by phenotypic and molecular methodology (Auad et al 2017), was briefly cultured on blood agar (BA) plates, and bacterial colonies were collected using sterile, cotton-tipped swabs moistened with sterile PBS. Bacterial cells were quantified by standard methodology and approximately $10^{9} \mathrm{CFU}$ were suspended in $20 \mathrm{ml}$ of PBS and formalin was added to a final concentration of $0.2 \%(\mathrm{v} / \mathrm{v})$. Cells were incubated overnight at $4{ }^{\circ} \mathrm{C}$. Aliquots of $100 \mu \mathrm{l}$ of the bacterial suspension were plated onto BA plates, incubated at $37^{\circ} \mathrm{C}$ and monitored daily for 5 days to confirm bacterial killing. Bacterial cells were pelleted by centrifugation at 3,000 $\mathrm{g}$ and resuspended in PBS. The vaccines were formulated using a different adjuvant. Aluminum hydroxide (Alhydrogel ${ }^{\mathrm{TM}}$ ) was added to bacterial suspension to $15 \%$ (v/v) final concentration and incubated during $1 \mathrm{~h}$ at 100 rpm. Immune stimulating particles (ISPA) were added to bacterial suspension at $2 \mathrm{mg} / \mathrm{ml}$ final concentration and mixed by inversion (Bertona et al 2017).
ANIMALS AND TREATMENTS

Twenty three pregnant goats in the last trimester of gestation and thirty goat kids obtained by crossbreeding Criollo x Anglo Nubian and belonging to a goat farm located in Córdoba province, Argentina, were randomly allocated to three groups: G1 (control group): 9 goats vaccinated with saline solution and 13 goat kids; G2: 8 female goats vaccinated with FKC of C. pseudotuberculosis in $\mathrm{Al}(\mathrm{OH})_{3}$ adjuvant and 8 goat kids; and $\mathrm{G} 3: 6$ goats vaccinated with FKC of C. pseudotuberculosis in ISPA adjuvant and 9 goat kids.

Goats were immunised subcutaneously behind the front leg with $1 \mathrm{ml}$ of vaccine at approximately 110 (first dose) and 131 (second dose) days of gestation according to the expected day of parturition. Goats were bled by puncture of the jugular vein before immunisation (T0), 21 days after first immunisation (T1), and at the time of parturition (T2). Newborns were bled 48 hours after birth. Blood was allowed to clot and sera were collected and centrifuged at $1000 \mathrm{x}$ g for 10 minutes.

After parturition, colostrum samples were collected and centrifuged at $13,800 \mathrm{x}$ g for 10 minutes, supernatants were collected and stored at $-80{ }^{\circ} \mathrm{C}$ until processing.

All the procedures were carried out according to the Guide for the Care and Use of Agricultural Animals in Agricultural Research and Teaching ${ }^{1}$.

\section{SEROLOGY}

Antibodies (total IgG) against C. pseudotuberculosis were measured by ELISA. Flat-bottomed 96-well microtitre plates were coated with a suspension of bacterin (1x10 $\mathrm{CFU} /$ well) in PBS (pH 7.2) as previously described (Camussone et al 2013). The coated plates were first incubated with 5\% low-fat cow milk in PBS and then with goat's sera or colostrum diluted in PBS or with PBS only as blank control. Between each step, plates were washed three times with $0.05 \%$ Tween 20 in PBS. After washing, peroxidase-conjugated rabbit anti-goat IgG (Pierce®) was added. All incubations were $1 \mathrm{~h}$ at $37^{\circ} \mathrm{C}$. Lastly, enzyme substrate $\left(\mathrm{H}_{2} \mathrm{O}_{2}\right.$ /tetrametylbenzidine $)$ was added and the reaction was stopped by the addition of $0.25 \mathrm{~m}-\mathrm{H}_{2} \mathrm{SO}_{4}$. The absorbance was read at $450 \mathrm{~nm}$ (Infinite ${ }^{\circledR}$ F50, Tecan, Austria) as previously described (Camussone et al 2013). Antibody levels were expressed as optical density (OD). Samples were assayed in duplicate. Working dilutions of goats sera, goat kids sera and colostra were 1/5000, 1/2500 and $1 / 10000$, respectively.

\footnotetext{
1 FASS, Federation of Animal Sciences Societies. 2010. Guide for the care and use of agricultural animals in research and teaching. $3^{\text {rd }}$ ed. FASS Champaign, Ilinois, USA; http://www.fass.org/docs/ agguide3rd/Ag_Guide_3rd_ed.pdf
} 
STATISTICAL ANALYSIS

In order to test the differences caused by immunisation, one way repeated measures Anova was performed using Rank transformation because the residuals are not normal and homoscedastic (Sokal and Rohlf 1995). One way Anova on colostrum and kid sera values was performed. In all the cases, Student Newman Keuls post hoc was performed, significance was $5 \%$ and the software used was $\mathrm{R}$ version 3.3.2 (R Core Team 2016). Mean and standard deviations were reported.

\section{RESULTS AND DISCUSSION}

\section{ANTIBODY RESPONSE IN SERA}

No differences in antibodies levels against C. pseudotuberculosis were detected at T0 between animals in $\mathrm{Al}(\mathrm{OH})_{3}$, ISPA or control groups. At 21 days after the first immunisation (T1), the group of animals vaccinated with bacterin formulated with $\mathrm{Al}(\mathrm{OH})_{3}(\mathrm{G} 2)$ showed significant differences with respect to the control group (G1), while no differences were observed between the group vaccinated with bacterin formulated with ISPA (G3) and the control group (G1). At the time of birth (T2) both vaccinated groups showed significant differences with respect to the control group (table 1).

Anti IgG specific response between goats from the same group was also compared. No differences in $\operatorname{IgG}$ levels were observed within the control group at any sampling time (G1). In goats vaccinated with bacterin formulated with $\mathrm{Al}(\mathrm{OH})_{3}(\mathrm{G} 2)$, differences in serum $\mathrm{IgG}$ levels between $\mathrm{T} 0$ and $\mathrm{T} 1$ were observed. However, after administration of the second vaccine dose (T2), IgG levels did not increase significantly. In G3 (animals vaccinated with ISPA as adjuvant), significant differences were found between $\mathrm{T} 0$ and $\mathrm{T} 1$ and between $\mathrm{T} 1$ and $\mathrm{T} 2$ (figure 1). The antibody response presented significant changes in time $(\mathrm{F}=58.641 ; \mathrm{P}<0.001)$ and this changes were related to the effect of immunisation ( $\mathrm{F}=8,698 ; \mathrm{P}=0.002)$ and to the interaction between them $(\mathrm{F}=41,497 ; \mathrm{P}<0.001)$.

After the administration of two doses of vaccine, both immunised groups showed an increase in $\mathrm{IgG}$ specific for $C$. pseudotuberculosis. In previous studies carried out in two groups of goats, one inoculated with secreted C. pseudotuberculosis antigen associated with Freund's incomplete adjuvant and the other group with oligodeoxynucleotide containing unmethylated $\mathrm{CpG}$ dinucleotides ( $\mathrm{CpG} \mathrm{ODN}$ ), a significant increase in humoral immune response after vaccination was observed (Moura-Costa et al 2008). However, differences between C. pseudotuberculosis antigens and adjuvants used for vaccines formulations, do not allow for direct comparisons with the present study.

There is little experience in the usage of immune stimulating complexes in the formulation of whole-cell vaccines. In a previous work, immunisation of pregnant heifers with a S. aureus bacterin formulated with ISCOMATRIX ${ }^{\mathrm{TM}}$ induced specific total IgG responses in sera and milk; higher than those obtained with the same immunogen formulated with $\mathrm{Al}(\mathrm{OH})_{3}$ (Camussone et al 2013). In addition, it was observed that ISCOMATRIX ${ }^{\mathrm{TM}}$ adjuvant associated with viral antigens generated enhanced and accelerated immune responses in mice and Guinea pigs (reviewed by Maraskovsky et al 2009). These observations differ from results obtained in the present study, since regardless of the adjuvant used, the total $\mathrm{IgG}$ response did not differed significantly between vaccinated groups, both in serum and colostrum. However, direct comparisons with previous studies are difficult due to differences in the antigens (bacterin vs viral antigens), animal species and adjuvants used.

\section{ANTIBODIES IN COLOSTRUM}

Immunised goats yielded significantly higher levels of anti- C. pseudotuberculosis specific IgG antibodies in colostrum than goats from the control group. No differences were observed in $\mathrm{IgG}$ levels between animals in $\mathrm{Al}(\mathrm{OH})_{3}$ or ISPA groups (table 2).

PASSIVE TRANSFER OF ANTI-C. pseudotuberculosis SPECIFIC ANTIBODIES

At 48 hours post-birth, newborns from immunized goats evidenced significantly higher levels of $\operatorname{IgG}$ anti- $C$. pseudotuberculosis in sera than those from control mothers; being $\mathrm{IgG}$ levels in newborns from $\mathrm{Al}(\mathrm{OH})_{3}$ group similar

Table 1. Antibody levels in pregnant goats immunised with a C. pseudotuberculosis vaccine formulated with different adjuvants at different times of study (T0: before immunisation; T1: 21 days after first immunisation; T2: time of parturition)*. OD means and standard deviation (SE) of IgG specific in goat's serum. Different letters imply significant differences.

\begin{tabular}{|c|c|c|c|c|c|c|c|c|c|c|}
\hline & \multicolumn{3}{|c|}{ T0 } & \multicolumn{3}{|c|}{$\mathrm{T} 1$} & \multicolumn{3}{|c|}{$\mathrm{T} 2$} & \multirow{2}{*}{ Overal } \\
\hline & & Mean & SE & & Mean & SE & & Mean & SE & \\
\hline CONTROL (G1) & A & 0.1272 & 0.0232 & A & 0.1184 & 0.0235 & A & 0.1110 & 0.0179 & A \\
\hline $\mathrm{Al}(\mathrm{OH})_{3}$ adjuvant $(\mathrm{G} 2)$ & A & 0.1213 & 0.0138 & B & 0.2310 & 0.1942 & B & 0.3710 & 0.2617 & B \\
\hline ISPA adjuvant (G3) & A & 0.1119 & 0.0123 & $\mathrm{AB}$ & 0.2134 & 0.0669 & B & 0.4148 & 0.1627 & B \\
\hline
\end{tabular}

*Differences between groups at different times were analysed. 
Table 2. Antibody levels in colostrum of goats and sera of goat kids following immunisation of pregnant goats with a $C$. pseudotuberculosis vaccine formulated with different adjuvants. OD means and standard deviation (SE) of IgG specific in colostrum and goat kid's serum. Different letters imply significant differences.

\begin{tabular}{lcccccccc}
\hline & \multicolumn{3}{c}{ Colostrum } & & \multicolumn{3}{c}{ Goat kids (48 hours) } \\
\cline { 2 - 4 } \cline { 7 - 9 } & & Mean & SE & & & Mean & SE \\
\hline CONTROL (G1) & A & 0.1318 & 0.0306 & & A & 0.1179 & 0.022 \\
Al(OH) $)_{3}$ adjuvant (G2) & B & 0.8059 & 0.4897 & & B & 0.5409 & 0.1962 \\
ISPA adjuvant (G3) & B & 0.7593 & 0.3782 & & B & 0.7117 & 0.2179 \\
\hline
\end{tabular}

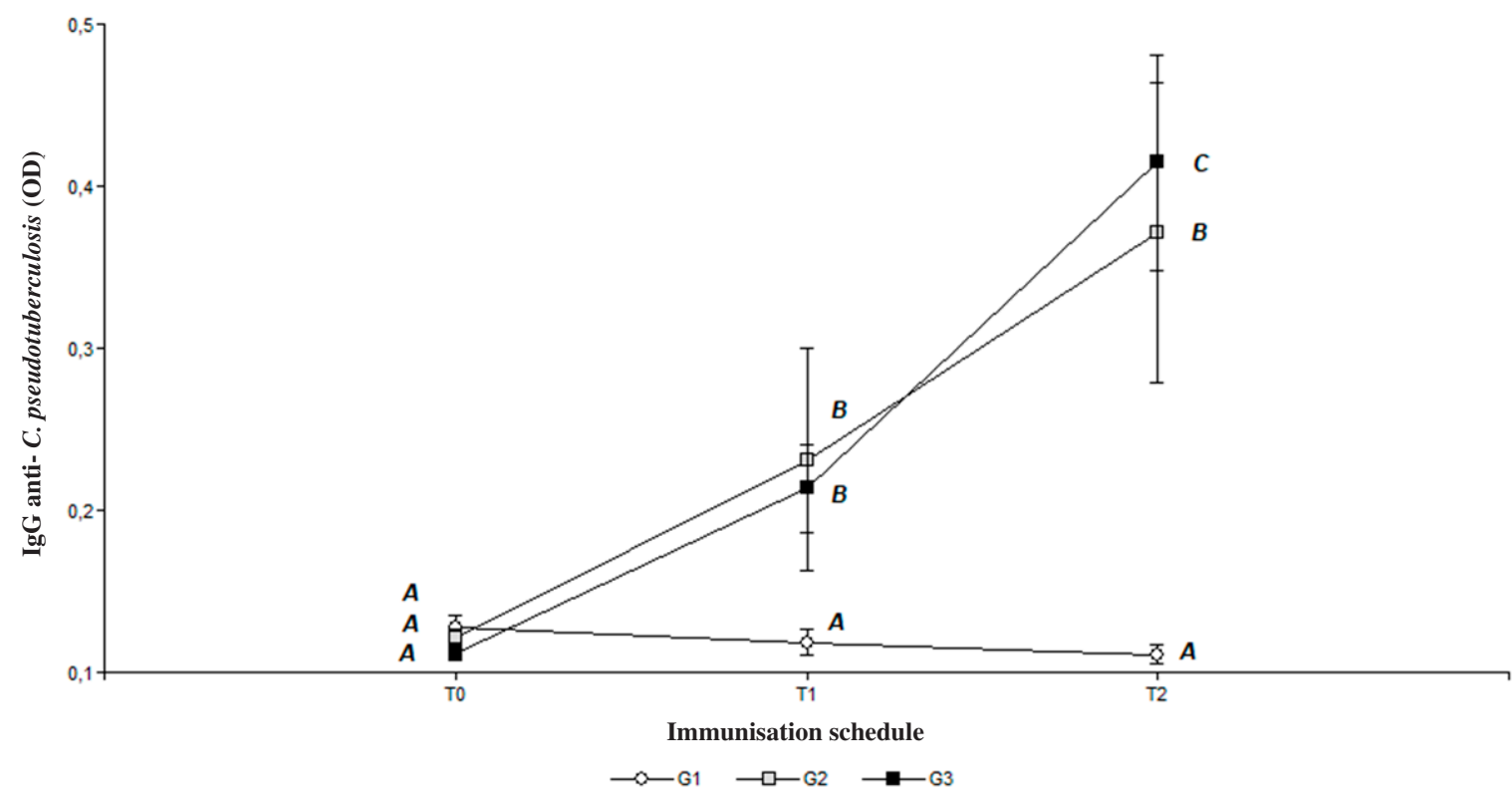

Figure 1. Serum antibody levels within each group of pregnant goats immunised with a C. pseudotuberculosis vaccine formulated with different adjuvants over time (T0: before immunization; T1: 21 days after first immunisation; T2: time of parturition)*. Specific IgG is expressed in OD. References: G1: control; G2: FKC in $\mathrm{Al}(\mathrm{OH})_{3}$ adjuvant; G3: FKC in ISPA adjuvant. Different letters imply significant differences. *Differences within the same treatment group over sampling time were analysed.

to those from ISPA group (table 2). A higher concentration of specific colostral antibodies was observed in vaccinated animals, regardless of the vaccine used. In the present study, both evaluated formulations achieved the passive transfer of immunity to goat kids. Although no direct comparisons can be made due to the different nature of vaccines employed, the manufacturer of a commercial C. pseudotuberculosis vaccine for goats (Glanvac® 3 for goats - Zoetis - Australia), recommends to vaccinate pregnant naïve animals with 1 $\mathrm{ml}$ dose of vaccine at the time of mating and a booster vaccination 4 weeks before the expected time of kidding to allow protection of the kids the first 6 to 8 weeks of life due to the passage of antibodies through the colostrum. Regarding the vaccine evaluated in the present experiment, further studies will be needed to determine the antibodies half-life to design a vaccination schedule for the kids to allow for extended protection.
In conclusion, a strong specific total IgG response was observed for the vaccine formulated with both adjuvants without finding differences between the formulations used. However, this response was earlier in those goats that received the vaccine formulated with $\mathrm{Al}(\mathrm{OH})_{3}$ as an adjuvant. In addition, high levels of specific antibodies were transferred to the goat kids through colostrum from both immunised groups and no adverse reactions were observed in the vaccines inoculation sites.

\section{ACKNOWLEDGEMENTS}

The authors would like to thank the Secretary of Research of the Universidad Católica de Córdoba for their finance support. They also thank Dr. Iván Marcipar (Universidad Nacional del Litoral) for providing the ISPA adjuvant, and Dr. Gustavo Lagioia (Biogénesis Bagó) for providing the $\mathrm{Al}(\mathrm{OH})_{3}$ adjuvant. 


\section{REFERENCES}

Al-gaabary MH, Osman SA, Oreiby AF. 2009. Caseous lymphadenitis in sheep and goats: Clinical, epidemiological and preventive studies. Small Ruminant Res 87, 116-121.

Auad J, Cooper L, Cerutti J, Marcellino R, Neder VE, et al. 2017. Aislamiento y caracterización de Corynebacterium pseudotuberculosis biotipo ovis en Lama glama en Córdoba, Argentina. Revista Methodo 2, 1-5.

Baird GJ, Fontaine MC. 2007. Corynebacterium pseudotuberculosis and its role in ovine caseous lymphadenitis. J Comp Path 137, 179-210.

Belchior SE, Gallardo A, Abalos A, Jodor N, Jensen O. 2006. Actualización sobre linfoadenitis caseosa: el agente etiológico y la enfermedad. Rev Vet 23, 258-278.

Bertona D, Pujato N, Bontempi I, Gonzalez V, Gugliotta L, et al. 2017. Development and assessment of a new cage like particle adjuvant. $J$ Pharm Pharmacol. doi:10.111/jphp.12768

Brogden KA, Cutlip RC, Lehmkuhl HD.1984. Comparison of protection induced in lambs by Corynebacterium pseudotuberculosis whole cell and cell wall vaccines. Am J Vet Res 45, 2393-2395.

Brogden KA, Glenn JS, East N, Audibert F.1996. A Corynebacterium pseudotuberculosis bacterin with muramyl dipeptide induces antibody titers, increases the time of onset, and decreases naturally occurring external abscesses in sheep and goats. Small Ruminant Res 19, 161-168.

Brown CC, Olander HJ, Biberstein EL, Morse SM. 1986. Use of a toxoid vaccine to protect goats against intradermal challenge exposure to Corynebacterium pseudotuberculosis. Am J Vet Res 47, 1116-1119.

Cameron CM, Minnaar JL, Engelbrecht MM, Purdom MR. 1972. Immune response of merino sheep to inactivated Corynebacterium pseudotuberculosis vaccine. Onderstepoort J Vet Res 39, 11-24.

Camussone CM, Veaute CM, Porporatto C, Morein B, Marcipar IS, et al. 2013. Immune response of heifers against a Staphylococcus aureus $\mathrm{CP} 5$ whole cell vaccine formulated with ISCOMATRIX ${ }^{\mathrm{TM}}$ adjuvant. J Dairy Res 80, 72-80.

Cooper LG, Auad J, Cerutti J, Lozano A, Aguilar Sola MS. 2014. Dinámica de la transferencia de inmunoglobulina $\mathrm{G}$ en el binomio madre-cría de la especie caprina. Rev Vet 25, 105-108.

Eggleton DG, Middleton HD, Doidge CV, Minty DW.1991. Immunisation against ovine caseous lymphadenitis: comparison of Corynebacterium pseudotuberculosis vaccines with and without bacterial cells. Aust Vet $J$ 68, 317-319.

Fernández A, Ramos JJ, Loste A, Ferrer LM, Figueras L, et al. 2006. Influence of colostrum treated by heat on immunity function in goat kids. Comp Immunol Microbiol Infectious Dis 29, 353-364.
Fontaine MC, Baird G, Connor KM, Rudge K, Sales J, et al. 2006. Vaccination confers significant protection of sheep against infection with a virulent United Kingdom strain of Corynebacterium pseudotuberculosis. Vaccine 24, 5986-5996.

Iepema G, Eekeren N, Wagenaar JP. 2008. Effect of colostrum type on serum gamma globulin concentration, growth and health of goat kids until three months. Proceedings of the 16 th IFOAN Organic Word Congress, Modena, Italy.

Maraskovsky E, Schnurr M, Wilson NS, Robson NC, Boyle J, et al. 2009. Development of prophylactic and therapeutic vaccines using the ISCOMATRIX adjuvant. Immunol Cell Biol 87, 371-376.

Morein B, Sundquist B, Höglund S, Dalsgaard K, Osterhaus A. 1984. Iscom, a novel structure for antigenic presentation of membrane proteins from enveloped viruses. Nature 308, 457-460.

Morein B, Hu KF, Abusugra I. 2004. Current status and potential application of ISCOMs in veterinary medicine. Adv Drug Deliv Rev 56, 1367-1382.

Moura-Costa LF, Bahia RC, Carminati R, Vale VLC, Paule BJA, et al. 2008. Evaluation of the humoral and cellular immune response to different antigens of Corynebacterium pseudotuberculosis in Canindé goats and their potential protection against caseous lymphadenitis. Vet Immunol Immunopathol 126, 131-141.

Palmero S, Smeriglio A, Salinas F, Gallagher M, Gómez L, et al. 2013. Presentación de un caso de linfoadenitis caseosa en caprinos de la Región Centro de Santa Fe. XIV Jornada de Divulgación TécnicoCientíficas, Facultad de Ciencias Veterinarias, Universidad Nacional de Rosario, Rosario, Argentina.

R Core Team. 2016. $R$ : A language and environment for statistical computing. R Foundation for Statistical Computing, Vienna, Austria.

Rudovsky A, Locher L, Zeyner A, Sobiraj A, Wittek T. 2008. Measurement of immunoglobulin concentration in goat colostrum. Small Rum Res 74, 265-269.

Sjölander A, Cox JC, Barr IG.1998. ISCOMs: an adjuvant with multiple functions. J Leukoc Biol 64, 713-723.

Sokal, R, Rohlf J. 1995. Biometry. The principles and practice of statistics in biological research. $3^{\text {rd }}$ ed. Freeman, Nueva York, ISBN 0-71-672411-1, Pp 445-447.

Suárez VH, Rosseto CD, Gaido AB, Salatin AO, Bertoni EA, et al. 2015. Prácticas de manejo y presencia de enfermedades en majadas caprinas de la región del chaco salteño. Vet Arg 32, 1-25.

Suárez VH, Dodero AM, Nievas JD, Martínez GM, Bertoni EA, et al. 2016. Presencia de enfermedades en majadas caprinas de las quebradas áridas de Jujuy y Salta. Vet Arg 33, 1-25.

Sun HX, Xie Y, Ye YP. 2009. ISCOMs and ISCOMATRIX ${ }^{\mathrm{TM}}$. Vaccine $27,4388-4401$. 
